\title{
(2) OPEN ACCESS \\ Alternative treatments for type 2 diabetes and associated metabolic diseases: medical therapy or endoscopic duodenal mucosal remodelling?
}

\author{
Annieke C G van Baar, ${ }^{1}$ Suzanne Meiring, ${ }^{1}$ Frits Holleman, ${ }^{2}$ David Hopkins, ${ }^{3}$ \\ Geltrude Mingrone (1) ${ }^{4,5}$ Jacques Devière, ${ }^{6}$ Max Nieuwdorp 우 , \\ Jacques J G H M Bergman (i) ${ }^{1}$
}

\section{ABSTRACT}

${ }^{1}$ Gastroenterology and Hepatology, Amsterdam UMC Location AMC, Amsterdam, The Netherlands

Internal Medicine, Amsterdam UMC Location AMC, Amsterdam, The Netherlands ${ }^{3}$ Institute of Diabetes, Endocrinology and Obesity, King's Health Partners, London, UK

${ }^{4}$ Internal Medicine, Universita Cattolica del Sacro Cuore, Rome, Italy

${ }^{5}$ Diabetes, King's College London School of Medical

Education, London, UK ${ }^{6}$ Gastroenterology and Hepatopancreatology, Erasme University Hospital, Brussels, Belgium

${ }^{7}$ Vascular Medicine, Amsterdam UMC Location AMC

Amsterdam, The Netherlands

Correspondence to

Professor Jacques J G H M Bergman, Gastroenterology and Hepatology, Amsterdam UMC Location AMC, Amsterdam 1105 $A Z$, The Netherlands; j.j.bergman@amsterdamumc.nl

ACGvB and SM contributed equally.

Received 5 May 2021

Accepted 24 June 2021

Published Online First

8 September 2021

Check for updates

(C) Author(s) (or their employer(s)) 2021. Re-use permitted under CC BY-NC. No commercial re-use. See rights and permissions. Published by BMJ.

To cite: van Baar ACG Meiring $S$, Holleman $F_{\text {, et al }}$ Gut 2021;70:2196-2204.

\section{INTRODUCTION}

The number of patients with type 2 diabetes (T2D) worldwide is expected to increase from 463 million in 2019 to 700 million in 2045, with a prevalence of more than $10 \%$ in Europe. Besides a role for genetics, causative factors include obesity, diet high in refined sugar and fat, and sedentary lifestyle. These factors may contribute to increased hepatic and peripheral insulin resistance, and thereafter pancreatic beta cells increase their insulin production to facilitate glucose uptake. This increased demand ultimately leads to pancreatic beta cell depletion, failure and cell death, resulting in metabolic decompensation, hyperglycaemia and overt hyperglycaemia. Eventually, macrovascular and microvascular complications develop following long-standing hyperglycaemia, accounting for significant morbidity and mortality in patients with T2D. Cardiovascular events are the major cause of death in patients with T2D.

Although there have been many important advances in oral and injectable medications since the millennium, overall control of blood glucose remains suboptimal in published audits from many countries and there is still a need for new treatment modalities that may impact on the management and natural history of T2D. In this review we consider emerging evidence on new techniques based on ablation of the duodenal mucosa and consider the potential place of this approach in the future management of T2D. ${ }^{12}$

\section{Content of this review}

First, we provide background information about the medical treatment options for T2D with an explanation of the current guidelines. This is followed by the surgical treatment options for T2D, where the proximal small bowel seems to play a key role. Next, we summarise the clinical studies conducted using the first endoscopic duodenal ablation (remodelling) technique: duodenal mucosal resurfacing (DMR). This is followed by a section about the potential mechanisms of DMR, a critical reflection on the clinical outcomes of DMR so far and methodological lessons learnt from these studies. Thereafter, we elaborate on other potential duodenal ablation techniques, as DMR has initiated interest

\section{Key messages}

- Despite important and promising advances in oral and injectable glucose-lowering medications for type 2 diabetes, overall control of blood glucose remains suboptimal in most patients.

- Bariatric surgery has revealed the proximal small bowel as an important contributor to metabolic benefits post surgery, making it a target for endoscopic treatment options.

- Duodenal mucosal resurfacing (DMR) is an endoscopic procedure where the duodenal mucosa is ablated to treat type 2 diabetes.

- DMR leads to improved glycaemia and additional metabolic improvements, such as liver fat reduction, without the disadvantages of anatomy-changing surgery.

- Clinical studies suggest that DMR has the best resultsin patients with high insulin resistance at study entry, pointing at an important role for patient selection.

- DMR may not be the only way to safely and effectively ablate the duodenal mucosa. New duodenal ablation techniques are under investigation, such as submucosal laser ablation and a technique using pulsed electric fields.

- The 'metabolic endoscopy field' is a promising new research area which may change the management of type 2 diabetes and which may significantly impact the endoscopy practises of gastroenterologists. To push this field forward, we need an integrated approach to study effects in both human and preclinical models to unravel the underlying mechanism, optimise effects and ultimately improve management of type 2 diabetes and metabolic syndrome.

- At this moment, duodenal ablation cannot replace drug-based type 2 diabetes management.

in this as a new endoscopic field. We continue with a look at the next few years, where we will probably see a plethora of new duodenal ablation techniques emerge, and we make recommendations for mechanistic studies to unravel the rather complex mechanism of action. We conclude with an answer to the 
Table 1 Overview of the most frequently prescribed glucose-lowering medications to treat type 2 diabetes mellitus

\begin{tabular}{|c|c|c|c|c|}
\hline $\begin{array}{l}\text { Medication (route of } \\
\text { administration) }\end{array}$ & Mechanism of action & $\begin{array}{l}\mathrm{HbA} 1 \mathrm{c} \text { reduction } \\
(\mathrm{mmol} / \mathrm{mol})\end{array}$ & Benefits & $\begin{array}{l}\text { Common side effects and } \\
\text { disadvantages }\end{array}$ \\
\hline Metformin (oral) & $\begin{array}{l}\text { Reduces intestinal glucose absorption. } \\
\text { Reduces hepatic glucose production. } \\
\text { Increases insulin sensitivity. }\end{array}$ & 11 & $\begin{array}{l}\text { Cheap. } \\
\text { Effective. } \\
\text { No hypoglycaemia. } \\
\text { Long-term safety profile. }\end{array}$ & $\begin{array}{l}\text { Diarrhoea, headache, change in } \\
\text { taste. } \\
\text { Caution with impaired renal } \\
\text { function. } \\
\text { - Low risk of lactic acidosis. }\end{array}$ \\
\hline SGLT2 inhibitor (oral) & $\begin{array}{l}\text { Prevents glucose reabsorption in the kidney } \\
\text { (proximal convoluted tubules). }\end{array}$ & $7-9$ & $\begin{array}{l}\text { Hypoglycaemia is rare. } \\
\text { Reduces cardiovascular } \\
\text { mortality and morbidity. }\end{array}$ & - Genital infections. \\
\hline $\begin{array}{l}\text { Sulfonylurea derivative } \\
\text { (gliclazide preferred) (oral) }\end{array}$ & $\begin{array}{l}\text { Stimulates pancreatic beta cells to produce } \\
\text { insulin (independent of glucose levels). }\end{array}$ & 17 & $\begin{array}{l}\text { Cheap. } \\
\text { Effective oral treatment. }\end{array}$ & $\begin{array}{l}\text { Weight gain. } \\
\text { Risk of hypoglycaemia. }\end{array}$ \\
\hline $\begin{array}{l}\text { Insulin } \\
\text { (subcutaneous injections) }\end{array}$ & $\begin{array}{l}\text { Stimulates glucose uptake in fat and skeletal } \\
\text { muscle. } \\
\text { Stimulates glycogen synthesis. } \\
\text { Inhibits hepatic glycogenolysis and } \\
\text { gluconeogenesis. } \\
\text { Inhibits lipolysis. }\end{array}$ & Dose-dependent & $\begin{array}{l}\text { Most effective for severe } \\
\text { hyperglycaemia. } \\
\text { Quick effect. }\end{array}$ & $\begin{array}{l}\text { Weight gain. } \\
\text { Risk of hypoglycaemia. } \\
\text { Injection-related complications. }\end{array}$ \\
\hline
\end{tabular}

DPP-4, dipeptidyl peptidase-4; GLP-1, glucagon-like peptide-1; HbA1c, haemoglobin A1c; SGLT2, sodium-glucose cotransporter 2.

question: can intestinal mucosal remodelling reduce the reliance on conventional glucose-lowering medication?

\section{CURRENT TREATMENT FOR T2D: GLUCOSE-LOWERING MEDICATIONS}

Treatment to achieve euglycaemia is important to prevent hyperglycaemia-related complications such as macrovascular and microvascular diseases in patients with T2D. Haemoglobin A1c (HbA1c) is the most important reflection of long-term glucose control and levels are closely monitored to measure the effect of glucose-lowering therapy and to adjust the medication regimen if necessary. Target HbA1c levels are $\leq 53 \mathrm{mmol} / \mathrm{L}(7 \%)$, or even $\leq 48 \mathrm{mmol} / \mathrm{L}(6.5 \%)$, depending on the applicable guidelines. ${ }^{3}$ Several lifestyle interventions, including reduction of carbohydrate intake and increase of physical exercise, are initially advised. This is however effective only in a subset of patients and has limited long-term results. ${ }^{45}$ Table 1 provides a summary of glucose-lowering therapies.

Metformin (dimethylbiguanide) is generally considered the first-line drug once lifestyle intervention is insufficient to achieve treatment goals. The first scientific reports on metformin date from 1922, and in Europe it has been registered and used since 1957. Its use as the first-line agent for T2D only became widespread in the late 1990s following its approval by the Food and Drug Administration in 1994 and the emergence of evidence from the landmark UK Prospective Diabetes Study of diabetes control which showed overall better outcomes and the possibility of lower cardiovascular mortality in a subset of patients who received the drug as initial pharmacotherapy. ${ }^{67}$ Metformin reduces glucose absorption in the gut, reduces hepatic glucose production and increases insulin sensitivity. Starting metformin treatment leads on average to an $\mathrm{HbA1c}$ reduction of approximately $11 \mathrm{mmol} / \mathrm{mol}(1 \%){ }^{8}$ Common side effects of metformin are diarrhoea and nausea. Caution is advised with impaired renal function, since metformin has been associated with lactic acidosis, particularly in case of renal failure. Nowadays, metformin has become the most prescribed glucoselowering therapy worldwide as it has a favourable long-term safety profile and is inexpensive. However, for the majority of patients with T2D (about 60\%), metformin monotherapy is not sufficient to achieve euglycaemia. ${ }^{9}$

As a next step, the most recent guidelines by the American Diabetes Association and the European Association for the Study of Diabetes ${ }^{10}$ advise to add either a glucagon-like peptide-1 receptor agonist (GLP-1RA), a dipeptidyl peptidase-4 inhibitor (DPP-4i) or a sodium-glucose cotransporter 2 inhibitor (SGLT2i) in patients with T2D and established cardiovascular disease, heart failure, or when there is a compelling need to minimise hypoglycaemia or to control weight. For the remaining patients or when cost is a major issue, sulfonylurea derivatives (SUs) are advised. This is in strong contrast to what happened for many years, when SUs were prescribed on top of metformin in nearly every patient. The next and final step for patients with T2D is insulin therapy. 


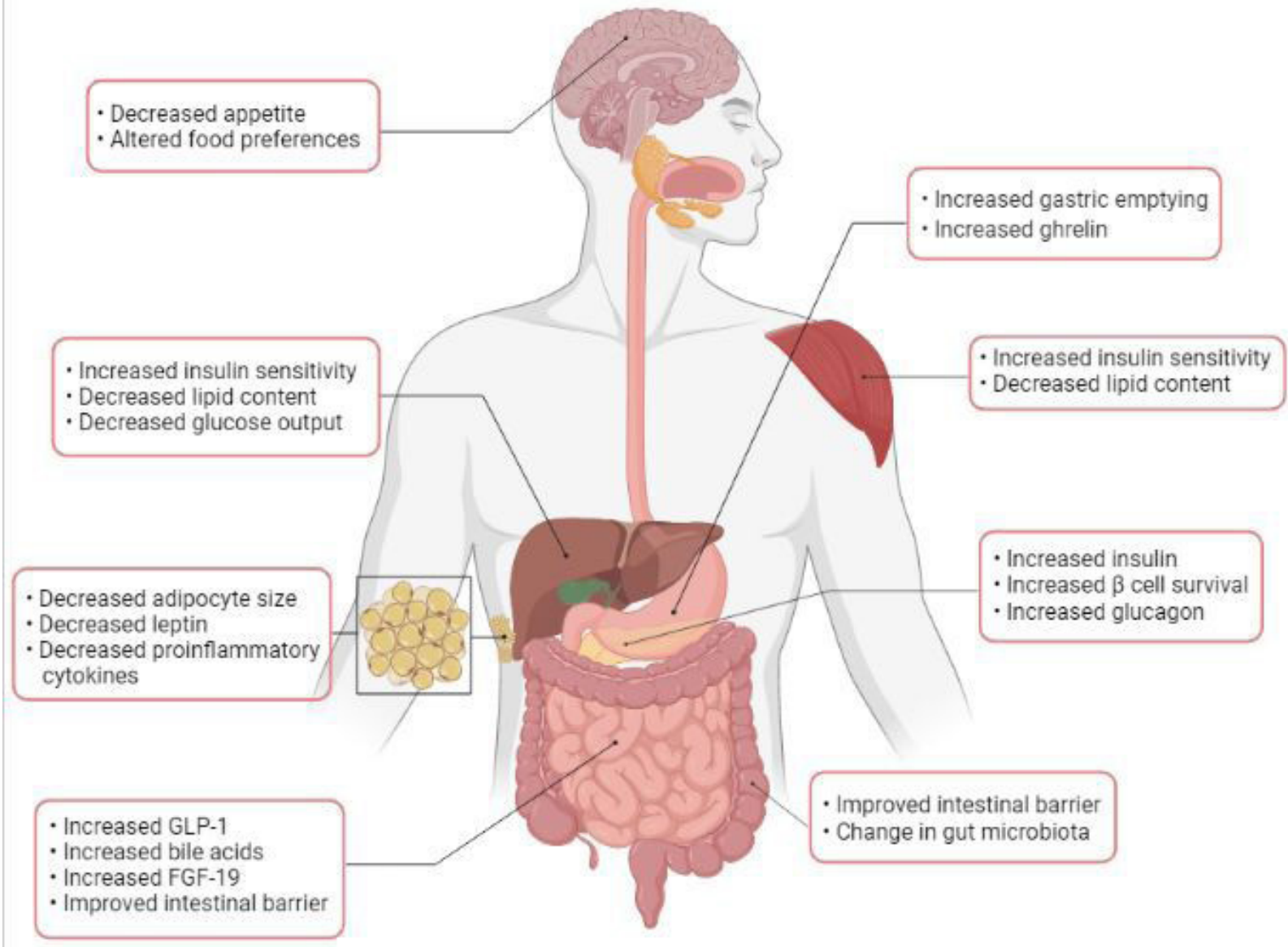

Figure 1 Complex metabolic changes induced by bariatric surgery and interventions involving the duodenum. Inspiration for this figure came from Madsbad et al . ${ }^{48}$ FGF-19, fibroblast growth factor 19.

GLP-1RAs have been approved since 2006 and are often prescribed before insulin therapy is initiated, depending on national guidelines. Glucagon-like peptide-1 (GLP-1) is a gut hormone (incretin) that is secreted into the bloodstream when food enters the GI tract. GLP-1 stimulates pancreatic insulin release, inhibits glucagon secretion and slows down gastric emptying. In patients with $\mathrm{T} 2 \mathrm{D}$, the incretin response is blunted and circulating GLP-1 levels are reduced. ${ }^{11}$ GLP1RAs improve insulin sensitivity and lower blood glucose, induce $2-6 \mathrm{~kg}$ of weight loss on average, reduce apoptosis of beta cells and increase their proliferation. GLP-1RAs can decrease $\mathrm{HbA} 1 \mathrm{c}$ by $13-20 \mathrm{mmol} / \mathrm{mol}(1.2 \%-1.8 \%) .{ }^{12}$ These medications are available as daily and once-weekly injectable forms, but oral GLP-1RAs have been developed. This would make GLP-1RAs an even more attractive treatment option for a broad patient population, particularly since they do not cause hypoglycaemia. GLP-1RAs are also proven to reduce cardiovascular outcomes in patients with increased risk of cardiovascular events. ${ }^{13}$ Common side effects are nausea and diarrhoea, which generally diminish on longer use. The high costs of GLP-1RA are however a significant disadvantage.

DPP-4i, also known as 'gliptins', block the action of dipeptidyl peptidase-4, an enzyme that breaks down GLP-1. They decrease HbA1c levels by $7-9 \mathrm{mmol} / \mathrm{mol}(0.6 \%-0.8 \%) .{ }^{14} \mathrm{DPP}-4 \mathrm{i}$ treatment is also associated with weight loss and does not cause hypoglycaemia. DPP-4i has an attractive safety profile, but data on hard cardiovascular endpoints have been disappointing. ${ }^{15-17}$
SGLT2i, also known as 'gliflozins', were approved in 2013. SGLT2i prevents glucose reabsorption in the proximal convoluted tubules of the kidney, thus increasing glucose levels in urine and decreasing blood glucose levels. This leads to an average decrease in $\mathrm{HbA} 1 \mathrm{c}$ of $7-9 \mathrm{mmol} / \mathrm{mol}(0.6 \%-0.8 \%){ }^{14}$ Additional beneficial effects of SGLT2i on cardiovascular mortality and morbidity are substantial. ${ }^{18}$ When using SGLT2i, patients lose $2-3 \mathrm{~kg}$ of weight on average. ${ }^{19}$ The most common side effects include urinary tract infections. Hypoglycaemia is rare and only seen when SGLT2 $i$ is combined with insulin or SUs. ${ }^{18}$

Nevertheless, all of the available medications require compliance by the individual patient on a daily or weekly basis, for example, administration of oral medications or injections, regular exercise, healthy nutrition and frequent blood glucose monitoring. Non-compliance greatly limits the impact of lifestyle modification and most pharmacological therapies. The more complex and labour-intensive a given treatment (eg, insulin administration) the more it reduces the real-world impact. $^{20}$

This explains why, despite this array of glucose-lowering medications, the proportion of patients with $\mathrm{T} 2 \mathrm{D}$ achieving treatment targets has not increased significantly. This proportion remains stable around $35 \%$ for patients treated by a specialist and around 50\% for patients treated by a primary care provider. ${ }^{21}$ Moreover, the HbA1c levels at which physicians introduce insulin have increased over time, as multiple 


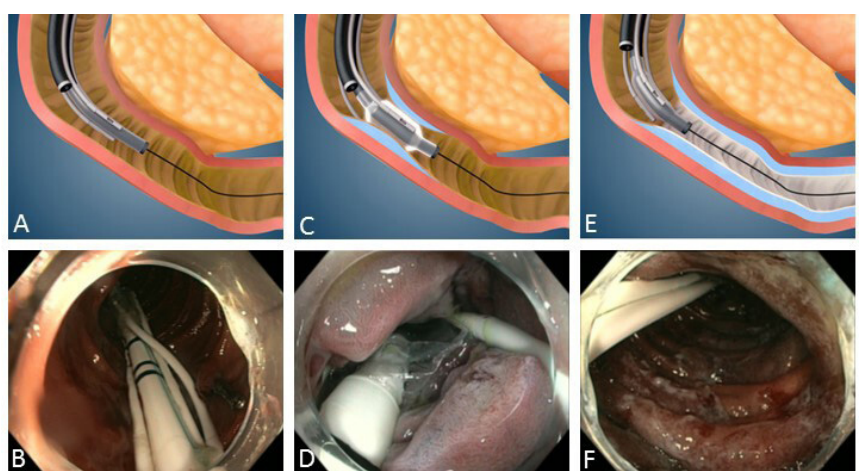

Figure 2 Illustrations with corresponding endoscopic views during the duodenal mucosal resurfacing (DMR) procedure: ( $A$ and $B$ ) introduction of the DMR catheter into the postpapillary duodenum; (C) submucosal lift and mucosal ablation; (D) postablation endoscopic view; ( $E$ and F) circumferentially ablated duodenal mucosa. Illustrations provided by Fractyl Laboratories.

other medications can be tried first. ${ }^{21}$ It seems that the broad array of glucose-lowering medications mainly adds to polypharmacy, confusion and non-compliance, without significant benefits so far. Considering that continuous administration is mandatory and that these medications do not halt disease progression, the need for disease-modifying interventions becomes clear.

\section{METABOLIC SURGERY AND THE PROXIMAL SMALL BOWEL IN T2D}

Bariatric surgery, also known as metabolic surgery, is superior to intensive lifestyle intervention and medical treatment of T2D. ${ }^{22} 23$ Joint clinical practice guidelines of the European Association for Endoscopic Surgery, the European Chapter of the International Federation for the Surgery of Obesity and Metabolic Disorders, and the European Association for the Study of Obesity state that bariatric/metabolic surgery should be considered for patients with body mass index (BMI) $\geq 30-35 \mathrm{~kg} / \mathrm{m}^{2}$, with poor glucose control despite optimal medical therapy. ${ }^{24}$ Improved glycaemic control is observed rapidly after surgery, occurs independent of changes in weight and is durable. It has therefore been proposed to consider bariatric surgery also in subjects with inadequately controlled T2D and a BMI as low as $30 \mathrm{~kg} / \mathrm{m}^{2}$, or $27.5 \mathrm{~kg} / \mathrm{m}^{2}$ for Asian individuals. ${ }^{25}$ However, these procedures are expensive, not easily reversible and come with some risk of perioperative and long-term complications and morbidity, which sometimes require repeated surgery. ${ }^{26}$ Therefore choosing metabolic surgery as a therapeutic option for patients with T2D requires careful consideration.

It has been demonstrated that bypassing the proximal small bowel is an important contributor to the metabolic benefits achieved after bariatric surgery, and this observation has been pivotal in the development of new non-pharmacological nonsurgical treatment options for patient with T2D. The great therapeutic potential and accessibility of the duodenum made it an attractive target for endoscopic treatments for T2D and concomitant metabolic diseases. ${ }^{27}$ Figure 1 provides an overview of the metabolic changes after metabolic surgery, which may also apply to interventions involving the duodenum.

\section{DMR: A BRIEF SUMMARY OF CLINICAL STUDIES}

DMR (Fractyl Laboratories, Lexington, Massachusetts, USA) is an endoscopic procedure involving catheter-based duodenal mucosal lifting and ablation (figure 2). It has been designed to treat T2D and can possibly convey beneficial effects on concomitant metabolic diseases such as non-alcoholic fatty liver disease (NAFLD). Preclinical research reported glycaemic improvements after duodenal abrasion in a controlled rodent study, and subsequent porcine studies suggested that hydrothermal ablation of the duodenal mucosa and superficial submucosa could be performed in a safe and effective way. ${ }^{28} \mathrm{~A}$ first-in-human study showed impressive HbA1c improvements; however, three patients developed duodenal stenosis. The length of the ablated duodenal segment was variable in this study. ${ }^{29}$ Before initiation of the subsequent European Revita-1 trial, the DMR procedure was optimised exclusively to reduce the time between submucosal injection and ablation, and consequently the risk of duodenal stenoses. ${ }^{30}$ In the single-arm Revita-1, the optimised DMR procedure was shown to be safe (mostly mild transient postprocedural adverse events) and showed significant efficacy in patients with T2D using oral glucose-lowering medications: an $\mathrm{HbA} 1 \mathrm{c}$ reduction of $10 \mathrm{mmol} / \mathrm{mol}(0.9 \%)$. Moreover, transaminase levels decreased and insulin sensitivity improved (Homeostatic Model Assessment for Insulin Resistance (HOMA-IR) reduction of 2.9 at 6 months). ${ }^{31}$ The 2 -year Revita-1 data suggest a durable effect. ${ }^{32}$ In the next randomised, sham-controlled Revita-2 study, the effect of DMR on HbA1c was not superior to sham in the overall population: $-10.4 \mathrm{mmol} / \mathrm{mol}(1.0 \%)$ in the DMR group compared with $-7.1 \mathrm{mmol} / \mathrm{mol}(0.7 \%)$ in the sham group $(p=0.147) .{ }^{33}$ It should however be noted that there was significant heterogeneity between the Brazil and the European population and therefore results were stratified by region. In the European population, the effect of DMR was significantly better compared with sham: $6.6 \mathrm{mmol} / \mathrm{mol}(0.6 \%)$ vs $3.3 \mathrm{mmol} / \mathrm{mol}$ $(0.3 \%)$ reduction in $\mathrm{HbA} 1 \mathrm{c}(\mathrm{p}=0.033)$. In addition, liver MRI proton density fat fraction (PDFF) revealed a significant reduction in liver fat content by $5.4 \%$ in the DMR group compared with $2.2 \%$ in the sham group $(\mathrm{p}=0.035)$. Furthermore, a post-hoc analysis demonstrated that for all patients with fasting plasma glucose $(\mathrm{FPG}) \geq 10 \mathrm{mmol} / \mathrm{L}$ at baseline, the median reduction in HbA1c 24 weeks post DMR was $14.2 \mathrm{mmol} / \mathrm{mol}$ compared with $4.4 \mathrm{mmol} / \mathrm{mol}$ in the sham group $(\mathrm{p}=0.002)$. The average weight loss of $3 \mathrm{~kg}$ was considered too little to be responsible for these effects, even if it is a potential bias to be considered. To date, the overall rate of serious adverse events is $2.5 \%$ and adverse events were mostly mild and transient.

In order to study the synergy between GLP-1RA and DMR, the single-arm uncontrolled INSPIRE pilot study was conducted in patients with T2D on once-daily long-acting insulin. A single DMR was combined with GLP-1RA administration to achieve discontinuation of insulin treatment. Results of this pilot study were promising. At 6 months, 69\% (11 of 16) of patients had adequate glycaemic control without the use of insulin. Additionally, multiple metabolic parameters improved, such as liver fat fraction, weight, insulin resistance and fasting insulin. ${ }^{34}$ Notably, patients had a total body weight loss of 9\% (probably due to both DMR and GLP-1RA), which could in part be responsible for the effects observed.

However, DMR did not increase insulin sensitivity in insulinresistant women with euglycaemia with polycystic ovary syndrome and obesity in the sham-controlled DOMINO trial. ${ }^{35}$

MECHANISM OF ACTION OF DUODENAL ABLATION IN T2D

There are currently multiple studies and analyses ongoing to investigate the mechanism of action of duodenal ablation. However, the mechanisms through which duodenal ablation 
might affect insulin resistance are not completely elucidated at this stage.

In rodent studies, the thickness of the duodenal mucosa is reduced after DMR (also referred to as reduction of 'hyperplasia'), but these changes have not yet been found in humans. Duodenal biopsies have been acquired and evaluated before and after DMR, yet mucosal and submucosal thickness of the duodenum was difficult (or even impossible) to determine. This could be due to the small tissue amount that can be collected through an endoscopic biopsy in combination with variability in tangential dissection of paraffin-embedded tissue small intestinal biopsy samples (observations from INSPIRE trial 2020, J Bergman, A van Baar and S Meiring, pending publication).

What is clear is that weight loss alone does not explain the effect of duodenal ablation on glycaemia. A systematic review examining the relationship between body weight change and effects on glycaemia concluded that $1 \mathrm{~kg}$ of weight loss accounts for an approximately $1 \mathrm{mmol} / \mathrm{mol}$ (or $\sim 0.1 \%$ ) lowering of HbA1c. ${ }^{36}$ On average, patients lose $2-3 \mathrm{~kg}$ of weight after DMR. Signs of nutritional deficiencies were not observed in patients after DMR. Therefore, we do not feel that (small intestinal) malabsorption can be held responsible for the effects of DMR.

One hypothesis is that a change in postprandial GLP-1 and gastric inhibitory polypeptide (GIP) production after DMR might be one of its mechanisms of action, comparable with the effect of GLP-1RA treatment. The duodenal mucosa is home to incretin hormone-producing cells, such as L cells producing GLP-1 and K cells producing GIP. In one of the first DMR studies, evidence was found of increased postprandial GLP-1 levels and decreased GIP levels after duodenal ablation (observations from Revita-1 trial 2020, J Bergman and A van Baar, pending publication 2021), but these results are yet to be confirmed by a larger, sham-controlled study.

An interaction between incretin and bile acids (BA) driven by modulation of the farnesoid $\mathrm{X}$ nuclear receptor has also been described, ${ }^{37}$ and in line with the preliminary results from the INSPIRE study suggests that BAs may mediate the postablation effect. We observed an increase in postprandial unconjugated and secondary BA levels following DMR. These are presumably partly the result of alterations in the intestinal microbiota, and this is currently being investigated (submitted to Physiological Reports in June 2021 by J Bergman, S Meiring and A van Baar).

Finally, in order to unveil other potential mechanisms of DMR's insulin-sensitising mechanism, a retrospective study involving DMR-treated patients from the first-in-human study and the Revita-1 study used targeted plasma metabolomics. ${ }^{38}$ Analyses indicated that plasma metabolite profiles associated with reduced inflammation, reduced oxidative stress, lowering of lipids and a decreased lactate to pyruvate ratio were seen that support favourable effects of duodenal ablation on metabolic fitness. These observed improvements in hepatic parameters could not be fully explained by the improved glycaemia or observed weight loss after the ablation. This implies that other mechanisms are responsible for this metabolic change and that duodenal ablation possibly alters local duodenal signalling in a manner that might favourably affect liver and metabolic health. Nevertheless, these data about potential underlying mechanisms come from uncontrolled studies with a limited sample size and large variability, and although interesting they are at best hypothesis-generating. Large, sham-controlled mechanistic studies investigating these specific metabolic mechanisms after duodenal ablation are required to unravel the mechanism of action in T2D and metabolic syndrome.

\section{REFLECTING ON THE CLINICAL OUTCOMES OF DMR: A CRITICAL APPRAISAL}

Although clinical results of the first uncontrolled DMR studies were encouraging, the subsequent results of the shamcontrolled Revita-2 study were not as clear, with heterogeneity in results by geographical region complicating the analysis of the effects on glycaemic control. Despite the fact that there was a significant additional effect of DMR over sham in the European population, the treatment effect was modest with a $3.3 \mathrm{mmol} / \mathrm{mol}$ greater reduction in $\mathrm{HbA} 1 \mathrm{c}$ over sham. In the overall population, the total effect of $-10.4 \mathrm{mmol} / \mathrm{mol} \mathrm{HbA} 1 \mathrm{c}$ after DMR is comparable with adding an extra oral glucoselowering medication to the existing treatment. This effect in the overall DMR population does not come close to the effect of bariatric surgery, and GLP-1RA treatment usually leads to a greater reduction in $\mathrm{HbA} 1 \mathrm{c}$ as well. ${ }^{39}{ }^{40}$ Preselecting patients with high insulin resistance, that is, patients with high fasting glucose levels and significant endogenous insulin production, may increase the efficacy of DMR; in the Revita-2 study, this group experienced a more impressive effect of DMR (HbA1c decrease of $14.2 \mathrm{mmol} / \mathrm{mol}$ vs $-4.4 \mathrm{mmol} / \mathrm{mol}$ in sham, $\mathrm{p}=0.002$ )

In the uncontrolled INSPIRE study, DMR was combined with GLP-1RA to replace basal insulin in patients with T2D. The results showed that $69 \%$ of patients were able to make a step back on the diabetes treatment ladder: namely off long-acting insulin at 6 months with the combination of DMR and GLP1RA. At 18 months, 53\% of the patients remained off insulin. Additionally, a substantial decrease in liver fat (liver MRI-PDFF) was observed. It is important to note that this was an uncontrolled pilot study and that a fairly liberal value $(58 \mathrm{mmol} / \mathrm{mol})$ for $\mathrm{HbA1c}$ was used as a criterion to resume insulin therapy. Prescribing a GLP-1RA in addition to insulin therapy in patients with T2D does lead to a reduction in $\mathrm{HbA1c}$, but insulin can only be completely discontinued in about $10 \%$ of the patients. ${ }^{41-43}$ The favourable results of INSPIRE gave impetus to initiation of a large, sham-controlled trial where DMR is being combined with medical therapy in order to achieve discontinuation of insulin treatment; initial results from this study are expected in $2022 .{ }^{44}$ Combining DMR with a specific medical therapy to elicit a probable synergistic effect might open up opportunities with greater clinical relevance for DMR as disease progression could potentially be slowed down.

In contrast to most pharmacological agents in routine use, DMR is associated with an improvement in insulin sensitivity. Moreover, patients with NAFLD (liver MRI-PDFF >5\%) showed a significant and clinically meaningful reduction in liver fat post DMR, confirming earlier findings of alanine transaminase (ALT) measurements. This differentiates the procedure from the current available pharmacological agents, as these neither improve insulin sensitivity nor improve NAFLD/non-alcoholic steatohepatitis (NASH).

It is important to note that all clinical DMR studies were conducted in patients with evidence of beta cell reserve, that is, sufficiently high endogenous plasma insulin or $\mathrm{C}$ peptide values. As clinical studies indicate that DMR improves insulin sensitivity, adequate endogenous insulin production is deemed necessary to benefit from this procedure.

At this stage, there are no data available on the effectiveness of second or repeated DMR procedures, but it is tempting to speculate that a second duodenal ablation adds to efficacy. Interval DMR would in our opinion be acceptable, looking at the reassuring safety profile of the DMR procedure, provided 


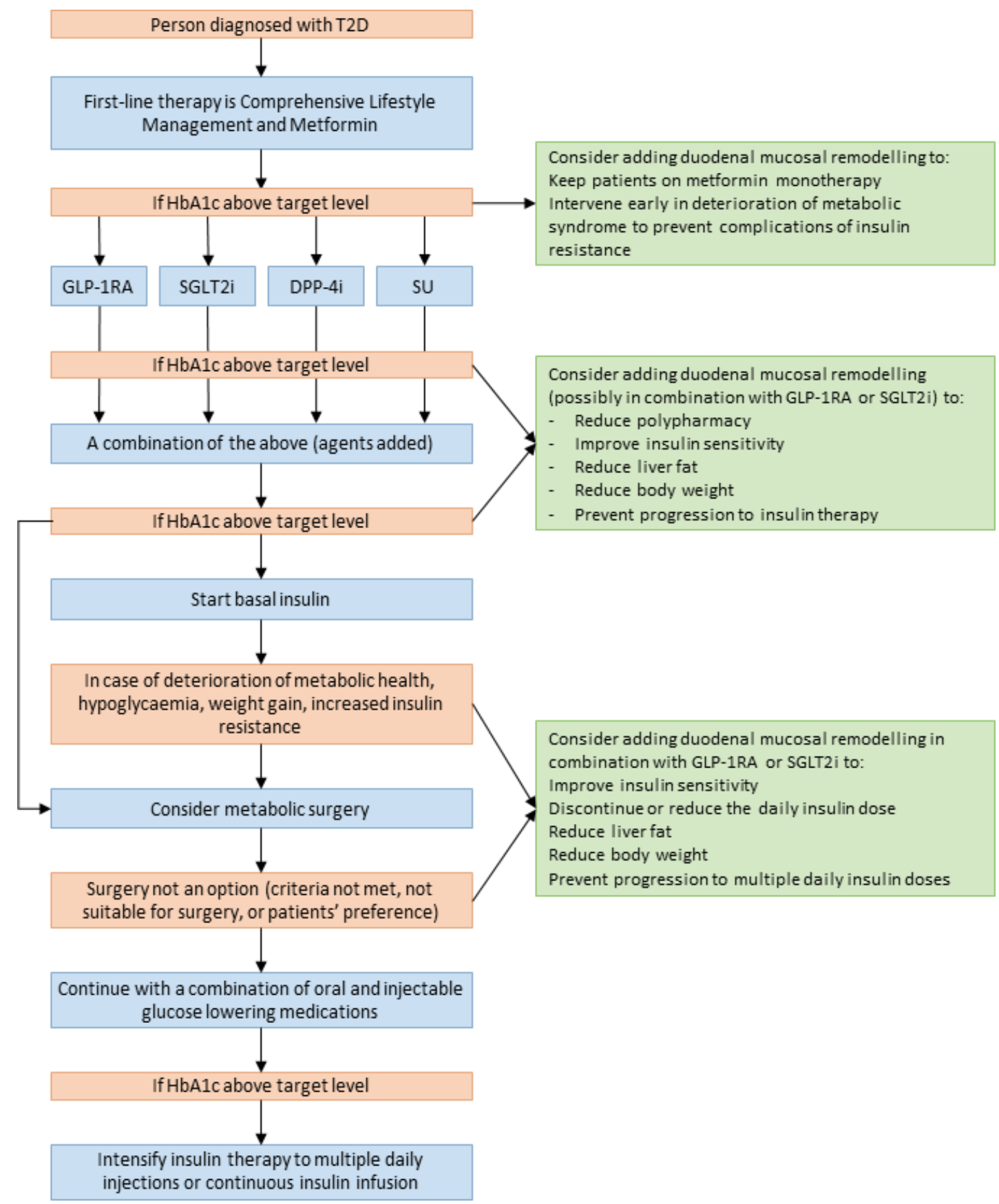

Figure 3 Proposed algorithm of where duodenal mucosal remodelling might fit in the current management of T2D. DPP-4i, dipeptidyl peptidase-4 inhibitor; GLP-1RA, glucagon-like peptide-1 receptor agonist; HbA1c, haemoglobin A1c; SGLT2i, sodium-glucose cotransporter 2 inhibitor; SU, sulfonylurea derivative; T2D, type 2 diabetes.

that adequate lifting of the submucosa by submucosal injection would be maintained after first ablation therapy. It is also important that sufficient beta cell capacity is ascertained before a repeat DMR procedure is performed.

\section{METHODOLOGICAL LESSONS LEARNT FROM THE FIRST DUODENAL ABLATION STUDIES}

The results of the conducted DMR studies are encouraging, but there are also methodological lessons learnt that are valuable for future duodenal ablation studies. First, it is imperative to include only patients who are compliant with their current medication and with residual endogenous insulin production and beta cell function. In poorly controlled patients, enrolment in a study with improved compliance of the baseline medication and lifestyle counselling may in itself lead to a profound effect which can obscure potential ablation effects. In the sham-controlled randomised Revita-2 study, patients enrolled in Brazil manifested an $\mathrm{HbA} 1 \mathrm{c}$ reduction of $-17.5 \mathrm{mmol} / \mathrm{mol}$ in the sham arm (vs $-20.2 \mathrm{mmol} / \mathrm{mol}$ in the DMR arm). For patients in Europe, who were enrolled with stable T2D disease, the sham effect was $-3.3 \mathrm{mmol} / \mathrm{mol}$ vs $-6.6 \mathrm{mmol} / \mathrm{mol}$ in the treatment arm. The sham effect in Brazil therefore was more than double the treatment effect in Europe. Second, as HbA1c levels represent glucose levels over a period of 3 months, a medication run-in period of at least 8 weeks, or preferably 12 weeks, is desirable. Third, as $\mathrm{T} 2 \mathrm{D}$ is a heterogeneous disease, it is critical to select the right 
patients. For DMR, these are patients with features of high insulin resistance (high HOMA-IR) accompanied by an adequate beta cell reserve (high fasting insulin and $\mathrm{C}$ peptide levels). Fourth, during trial conduct, uniform medication and diet management are critical in order to interpret the results on glycaemia. Fifth, the target population of patients with T2D is generally not treated in tertiary care study centres, but rather are managed by general practitioners. Initially, there was limited awareness among these primary care providers and patients about the possibility of duodenal ablation for T2D. We experienced that a media campaign enticed many patients with T2D to participate in studies involving a single duodenal ablation for treatment of T2D. Therefore, it is advisable to reach out to patients directly, instead of through their healthcare providers, although within the constraints placed by medical ethical committees.

\section{REFLECTING ON THE ENDOSCOPIC PROCEDURE OF DUODENAL ABLATION}

DMR is the first endoscopic duodenal ablation technique for T2D. The current single-balloon technique has been shown to be acceptable in terms of efficacy and safety. Nevertheless, the current procedure is far from optimal: the procedure time is considerable $(50 \mathrm{~min})$ and deep sedation and fluoroscopy are required. The technique also does not yet appear to be 'dummy-proof': the procedure involves inconvenient catheter and guidewire handling, which sometimes may be a challenge in the horizontal part of the duodenum. A success rate of $83 \%$ emphasises these technical challenges. With the transition from a double-catheter system to an integrated single balloon, the DMR system has matured, ${ }^{30}$ but a throughthe-scope device or quicker ablation technique (eg, without the need for submucosal lifting) would improve the practical application. In addition, DMR results in a 'patchy' ablation; that is, not the whole circumference of the mucosa appears to be effectively ablated. This is due to a preferential apposition of the balloon to one side of the duodenum, the possible space between adjacent ablation areas, and the presence of duodenal folds which may 'protect' some areas from contact with the balloon. This obviously leaves room to improve the efficacy of duodenal ablation techniques.

\section{OTHER DUODENAL ABLATION TECHNIQUES}

The currently available data on DMR for T2D have created interest in other potential ablation techniques for duodenal remodelling. The following techniques are currently under development or under clinical evaluation:

- Submucosal laser ablation targeting the submucosal nerve plexus. The Digma laser ablation balloon catheter (Digma Medical, Givat Shmuel, Israel) is inserted through the endoscope working channel, which logically is a more convenient approach for endoscopists than passing catheters on the outside of the endoscope. Ablation is performed sequentially through a set of parallel 'rings', with approximately $7 \mathrm{~mm}$ intervals, along the length of the exterior of an inflated balloon, forming an ablation set. After completion of each ablation set, the fibre optic catheter tip is retracted back and to a 'home position' and the balloon is deflated. At this stage the endoscope and balloon are retracted to the next ablation area, where the balloon is reinflated and the ablation process proceeds. A first-in-human study in nine patients demonstrated a favourable safety and tolerability profile and significant reductions in $\mathrm{HbA} 1 \mathrm{c}$ and in fasting and postprandial glucose levels. ${ }^{45}$ A sham-controlled study is being initiated in 2021.

- Duodenal mucosal regeneration using pulsed electric fields (PEF) (Endogenex, Plymouth, Minnesota, USA). The use of $\mathrm{PEF}$ is a completely new way of energy transmission in the GI tract. It may allow a regulated, non-thermal ablation of the duodenal mucosa, primarily inducing apoptosis instead of necrosis of duodenal mucosal cells. Preclinical testing is currently finalised with reassuring and encouraging results, with the potential of an insulin-sensitising effect. First-inhuman studies are scheduled for 2021. ${ }^{4647}$

- Radiofrequency ablation (RFA) with the Barrx device (Medtronic, Dublin, Ireland) is extensively used for Barrett's eradication with reassuring safety results, but it is not yet tested for duodenal ablation. RFA is undergoing preclinical testing for use in the duodenum.

- Steam ablation (Aqua Medical, Santa Ana, California, USA) is under clinical investigation for Barrett's oesophagus, but is currently also undergoing preclinical testing for use in the duodenum (www.aquaendoscopy.com). Steam ablation might have the advantage of not needing separate ablation cycles, as steam can be circulated through a secluded area of the duodenum without the need for contact-based ablations. Feasibility is therefore increased by reducing procedure time and increasing technical practicality. However, the available data for use in the oesophagus are still limited.

- Cryoablation (Pentax Medical, Tokyo, Japan) is also under clinical investigation for Barrett's oesophagus with preclinical testing for use in the duodenum (https://www.pentaxmedical.com/pentax/nl/107/1/ studies-further-validate-safety-efficacy-and-an-improvedpatient-experience-in-use-of-the-c2-cryoballoon-ablation-system-for-primary-treatment-of-barretts-esophagus). Cryoablation is thought to preserve the extracellular matrix with the potential advantage that it allows for deeper ablation without increasing the risk of stricture formation. Currently focal cryoballoon ablation is available for the GI tract, but large-area devices are on their way, which are desirable for use in the duodenum. Data about cryoballoon ablation for use in Barrett's oesophagus are accumulating with favourable and reassuring results.

The ideal duodenal ablation technique has a through-theendoscope design, should take less than $30 \mathrm{~min}$, works without the need for fluoroscopy or intubation, induces a homogeneous ablation of the targeted duodenal surface, possibly within a single application, and can be performed by a general endoscopist without extensive background in interventional endoscopy. Techniques that generate an ablation effect at the mucosal surface area (DMR, balloon-based laser ablation, electroporation or RFA) likely have a better efficacy-safety profile than techniques in which the ablation effect is generated intraluminally and is thus influenced by geometry and size of the lumen.

\section{WHAT WILL THE NEXT YEARS BRING IN DUODENAL ABLATION/METABOLIC PROCEDURES?}

The DMR ablation technique is more advanced in development than other techniques and a large-scale sham-controlled study in patients with T2D on insulin therapy was initiated in early 2021. The DMR technique is at this stage technically difficult so there is room for procedural improvements. We will likely see a plethora of new ablation techniques emerge, of which some may overcome the disadvantages and shortcomings of the current DMR technique. Clinical studies in the 
'metabolic endoscopy field' will likely benefit from the lessons learnt from previous duodenal ablation studies.

We expect many randomised controlled clinical studies investigating use of duodenal ablation to treat a variety of conditions with insulin resistance as their root cause, not only T2D but also NAFLD/NASH, for which we lack an appropriate treatment at this time.

We need an integrated approach to study metabolism before and after duodenal ablation in both human and preclinical rodent studies to unravel the mechanisms responsible for the metabolic and glycaemic improvements after duodenal remodelling. International collaborations or an international research consortium where clinicians (endocrinologists, gastroenterologists, endoscopists and hepatologists), biologists, bioinformatics specialists and laboratory specialists meet would be a welcome development.

\section{CONCLUSIONS: CAN DUODENAL MUCOSAL REMODELLING FOR DIABETES HELP REDUCE THE RELIANCE ON GLUCOSE- LOWERING MEDICATIONS?}

Duodenal ablation has the potency to become a treatment option for patients with T2D seeking a single intervention without the disadvantages of anatomy-changing surgery. For the right patients (ie, patients with features of high insulin resistance with still adequate beta cell capacity), DMR can significantly decrease $\mathrm{HbA} 1 \mathrm{c}$ with additional metabolic improvements such as a reduction in liver fat content. For some patients, the number and/or dose of glucose-lowering medications can be reduced after DMR. When DMR is combined with the right medication, patients on exogenous insulin therapy can actually discontinue insulin therapy while improving glycaemic and metabolic parameters. Figure 3 presents a proposed algorithm of where duodenal ablation would fit in the broader context of the multimodal management of a patient with T2D. However, current efficacy data are as yet insufficient to promote incorporation in standard management guidelines and duodenal ablation cannot replace drug-based management of T2D fully. Studies involving different types of ablation are underway and are expected to provide more information and improve the endoscopic possibilities for duodenal mucosal ablation.

Once studies have unravelled the underlying working mechanism of metabolic procedures, the current drug-based management of T2D and metabolic syndrome may be further improved. This will hopefully lead to a reduction in polypharmacy and improvement in overall HbA1c levels in patients with T2D. Since duodenal ablation offers a compliance-free therapeutic effect by a single endoscopic intervention, it may become an important part of diabetes management in selected patients, with the potential to become an indication for therapeutic interventions in gastroenterology.

Contributors ACGB, SM and JJGHMB wrote the first drafts. FH, DH, GM, JD and MN provided important intellectual input. All authors reviewed and discussed the content.

Funding MN is supported by a ZONMW VICl 2020 grant (grant number 09150182010020).

Competing interests MN is in the Scientific Advisory Board of Caelus Pharmaceuticals, The Netherlands, and Kaleido Biosciences, USA. None of these is directly relevant to the current paper. DH has received honoraria from Fractyl for participating in scientific advisory boards. There are no patents, products in development or marketed products to declare. The other authors declare no competing financial interests.

Patient and public involvement Patients and/or the public were not involved in the design, or conduct, or reporting, or dissemination plans of this research.
Patient consent for publication Not required.

Provenance and peer review Commissioned; externally peer reviewed.

Open access This is an open access article distributed in accordance with the Creative Commons Attribution Non Commercial (CC BY-NC 4.0) license, which permits others to distribute, remix, adapt, build upon this work non-commercially, and license their derivative works on different terms, provided the original work is properly cited, appropriate credit is given, any changes made indicated, and the use is non-commercial. See: http://creativecommons.org/licenses/by-nc/4.0/.

\section{ORCID iDs}

Geltrude Mingrone http://orcid.org/0000-0003-2021-528X

Max Nieuwdorp http://orcid.org/0000-0002-1926-7659

Jacques J G H M Bergman http://orcid.org/0000-0001-7548-6955

\section{REFERENCES}

1 Gudbjörnsdottir S, Cederholm J, Nilsson PM, et al. The National diabetes register in Sweden: an implementation of the St. Vincent Declaration for quality improvement in diabetes care. Diabetes Care 2003;26:1270-6.

2 NHS Digital. National diabetes audit programme, 2021. Available: https://digital.nhs. uk/data-and-information/clinical-audits-and-registries/national-diabetes-audit

3 American Diabetes Association. 6. Glycemic Targets: Standards of Medical Care in Diabetes-2021. Diabetes Care 2021;44:573-84.

4 Mai K, Brachs M, Leupelt $V$, et al. Effects of a combined dietary, exercise and behavioral intervention and sympathetic system on body weight maintenance after intended weight loss: results of a randomized controlled trial. Metabolism 2018;83:60-7

5 Look AHEAD Research Group. Eight-year weight losses with an intensive lifestyle intervention: the look AHEAD study. Obesity 2014;22:5-13.

6 Bailey CJ. Metformin: historical overview. Diabetologia 2017;60:1566-76.

7 Effect of intensive blood-glucose control with metformin on complications in overweight patients with type 2 diabetes (UKPDS 34). UK prospective diabetes study (UKPDS) group. Lancet 1998;352:854-65.

8 Saenz A, Fernandez-Esteban I, Mataix A, et al. Metformin monotherapy for type 2 diabetes mellitus. Cochrane Database Syst Rev 2005:Cd002966.

9 Sanchez-Rangel E, Inzucchi SE. Metformin: clinical use in type 2 diabetes. Diabetologia 2017;60:1586-93.

10 Buse JB, Wexler DJ, Tsapas A. Update to: management of hyperglycemia in type 2 diabetes, 2018. A consensus report by the American diabetes association (ADA) and the European association for the study of diabetes (EASD). Diabetes Care 2019;2020:487-93.

11 Nauck M, Stöckmann F, Ebert R, et al. Reduced incretin effect in type 2 (non-insulindependent) diabetes. Diabetologia 1986;29:46-52.

12 Aroda VR. A review of GLP-1 receptor agonists: evolution and advancement, through the lens of randomised controlled trials. Diabetes Obes Metab 2018;20(Suppl 1):22-33.

13 Kristensen SL, Rørth R, Jhund PS, et al. Cardiovascular, mortality, and kidney outcomes with GLP-1 receptor agonists in patients with type 2 diabetes: a systematic review and meta-analysis of cardiovascular outcome trials. Lancet Diabetes Endocrinol 2019;7:776-85.

14 Bolen S, Tseng E, Hutfless S. Diabetes medications for adults with type 2 diabetes: an update. Rockville, MD, 2016.

15 Kongwatcharapong J, Dilokthornsakul P, Nathisuwan S, et al. Effect of dipeptidyl peptidase-4 inhibitors on heart failure: a meta-analysis of randomized clinical trials. Int J Cardiol 2016;211:88-95.

16 Green JB, Bethel MA, Armstrong PW, et al. Effect of sitagliptin on cardiovascular outcomes in type 2 diabetes. N Eng/ J Med 2015;373:232-42.

17 Rosenstock J, Kahn SE, Johansen OE, et al. Effect of linagliptin vs glimepiride on major adverse cardiovascular outcomes in patients with type 2 diabetes: the Carolina randomized clinical trial. JAMA 2019:322:1155-1166.

18 Monami M, Dicembrini I, Mannucci E. Effects of SGLT-2 inhibitors on mortality and cardiovascular events: a comprehensive meta-analysis of randomized controlled trials. Acta Diabetol 2017:54:19-36.

19 Ribola FA, Cançado FB, Schoueri JHM, et al. Effects of SGLT2 inhibitors on weight loss in patients with type 2 diabetes mellitus. Eur Rev Med Pharmacol Sci 2017;21:199-211.

20 O'Connor PJ. Improving medication adherence: challenges for physicians, payers, and policy makers. Arch Intern Med 2006;166:1802-4.

21 Higgins V , Piercy J, Roughley A, et al. Trends in medication use in patients with type 2 diabetes mellitus: a long-term view of real-world treatment between 2000 and 2015 . Diabetes Metab Syndr Obes 2016;9:371-80.

22 Simonson DC, Halperin F, Foster K, et al. Clinical and patient-centered outcomes in obese patients with type 2 diabetes 3 years after randomization to Roux-en-Y gastric bypass surgery versus intensive lifestyle management: the SLIMM-T2D study. Diabetes Care 2018:41:670-9.

23 Schauer PR, Bhatt DL, Kirwan JP, et al. Bariatric Surgery versus Intensive Medical Therapy for Diabetes - 5-Year Outcomes. N Engl J Med 2017;376:641-51. 
24 Di Lorenzo N, Antoniou SA, Batterham RL, et al. Clinical practice guidelines of the European association for endoscopic surgery (EAES) on bariatric surgery: update 2020 endorsed by IFSO-EC, EASO and ESPCOP. Surg Endosc 2020;34:2332-58.

25 Cummings DE, Rubino F. Metabolic surgery for the treatment of type 2 diabetes in obese individuals. Diabetologia 2018;61:257-64.

26 Kassir R, Debs T, Blanc $\mathrm{P}$, et al. Complications of bariatric surgery: presentation and emergency management. Int J Surg 2016;27:77-81.

27 van Baar ACG, Nieuwdorp M, Holleman F, et al. The duodenum harbors a broad Untapped therapeutic potential. Gastroenterology 2018;154:773-7.

28 Haidry RJ, van Baar AC, Galvao Neto MP, et al. Duodenal mucosal resurfacing: proofof-concept, procedural development, and initial implementation in the clinical setting. Gastrointest Endosc 2019;90:673-81.

29 Rajagopalan $\mathrm{H}$, Cherrington AD, Thompson CC, et al. Endoscopic duodenal mucosal resurfacing for the treatment of type 2 diabetes: 6 -month interim analysis from the first-in-human proof-of-concept study. Diabetes Care 2016;39:2254-61.

30 van Baar ACG, Haidry R, Rodriguez Grunert L, et al. Duodenal mucosal resurfacing: multicenter experience implementing a minimally invasive endoscopic procedure for treatment of type 2 diabetes mellitus. Endosc Int Open 2020;8:E1683-9.

31 van Baar ACG, Holleman F, Crenier L, et al. Endoscopic duodenal mucosal resurfacing for the treatment of type 2 diabetes mellitus: one year results from the first international, open-label, prospective, multicentre study. Gut 2020;69:295-303.

32 van Baar ACG, Lopez-Talavera JC, White K. Durable glycemic and hepatic improvements after duodenal mucosal resurfacing in patients with type 2 diabetes. J Diabetes Sci Technol 2020:A115.

33 Mingrone G, van Baar AC, Devière J, et al. Safety and efficacy of hydrothermal duodenal mucosal resurfacing in patients with type 2 diabetes: the randomised, double-blind, sham-controlled, multicentre REVITA-2 feasibility trial. Gut 2021. doi:10.1136/gutjnl-2020-323608. [Epub ahead of print: 17 Feb 2021].

34 van Baar ACG, Meiring S, Smeele P, et al. Duodenal mucosal resurfacing combined with glucagon-like peptide-1 receptor agonism to discontinue insulin in type 2 diabetes: a feasibility study. Gastrointest Endosc 2021;94:111-20.

35 Dimitriadis GK, Kaur V, Pérez-Pevida B, et al. Investigation of the mechanism of action of duodenal mucosal resurfacing in insulin resistant women with polycystic ovarian syndrome. The domino multicentre randomised controlled trial. Endocrine Abstracts 2020;70.

36 Gummesson A, Nyman E, Knutsson M, et al. Effect of weight reduction on glycated haemoglobin in weight loss trials in patients with type 2 diabetes. Diabetes Obes Metab 2017;19:1295-305.
37 van Olst N, Meiring S, de Brauw M, et al. Small intestinal physiology relevant to bariatric and metabolic endoscopic therapies: incretins, bile acid signaling, and gut microbiome. Tech Innov Gastrointest Endosc 2020;22:109-19.

38 van Baar ACG, Beuers U, Wong K, et al. Endoscopic duodenal mucosal resurfacing improves glycaemic and hepatic indices in type 2 diabetes: 6 -month multicentre results. JHEP Rep 2019;1:429-37.

39 Monami M, Marchionni N, Mannucci E. Glucagon-like peptide-1 receptor agonists in type 2 diabetes: a meta-analysis of randomized clinical trials. Eur J Endocrinol 2009;160:909-17.

40 Mingrone G, Panunzi S, De Gaetano A, et al. Metabolic surgery versus conventional medical therapy in patients with type 2 diabetes: 10-year follow-up of an open-label, single-centre, randomised controlled trial. Lancet 2021;397:293-304.

41 Riddle MC, Aronson R, Home P, et al. Adding once-daily lixisenatide for type 2 diabetes inadequately controlled by established basal insulin: a 24-week, randomized, placebo-controlled comparison (GetGoal-L). Diabetes Care 2013;36:2489-96

42 Garvey WT, Birkenfeld AL, Dicker D, et al. Efficacy and safety of liraglutide $3.0 \mathrm{Mg}$ in individuals with overweight or obesity and type 2 diabetes treated with basal insulin: the scale insulin randomized controlled trial. Diabetes Care 2020;43:1085-93.

43 van Velsen EFS, Lamers J, Blok V, et al. A prospective study of concomitant GLP-1 analogue and insulin use in type 2 diabetes in clinical practice. Neth J Med 2014;72:523-7.

44 Clinicaltrials.Gov. Evaluation of the efficacy and safety of duodenal mucosal resurfacing using the Revita $\circledR$ system in subjects with type 2 diabetes on insulin therapy (REVITA-T2Di). Available: https://clinicaltrials.gov/ct2/show/NCT04419779

45 MRAZ M, MARCOVITCH I, LANKOVA I, et al. 1131-P: endoscopic duodenal submucosal laser ablation for the treatment of type 2 diabetes mellitus: results of first-in-human pilot study. Diabetes 2019;68:1131.

46 ClinicalTrials.Gov. Safety and feasibility of a novel endoscopic intervention for the treatment of type II diabetes (REGENT-1). Available: https://clinicaltrials.gov/ct2/show/ NCT04725890

47 Netherlands Trial Register. Trial NL9482. Available: https://www.trialregister.nl/trial/ 9482

48 Haluzík M, Kratochvílová H, Haluzíková D, et al. Gut as an emerging organ for the treatment of diabetes: focus on mechanism of action of bariatric and endoscopic interventions. J Endocrinol 2018;237:R1-17. 